\title{
Trayectorias conyugales de los inmigrantes internacionales en España ${ }^{1}$
}

\author{
Albert Esteve \\ Centre d'Estudis Demogràfics \\ aesteve@ced.uab.es \\ Clara Cortina \\ Consejo Superior de Investigaciones Científicas. Centro de Ciencias Humanas y Sociales \\ clara.cortina@cchs.csic.es
}

\section{Resumen}

Estudios recientes han mostrado la importancia de la dimensión familiar en la comprensión de los patrones migratorios actuales y en el refuerzo de los vínculos familiares transnacionales. Sin embargo, es necesario realizar análisis cuantitativos de la situación en el hogar de los inmigrantes internacionales en el momento que llegan a España y también con posterioridad. En este artículo, se analiza la formación de parejas y se propone un marco a través del cual se pueda clasificar los caminos seguidos por inmigrantes que viven en España según su estatus conyugal antes, durante y después de la migración. Se utilizan regresiones logísticas para analizar los datos de la Encuesta Nacional de Inmigración de 2007 sobre 15.384 inmigrantes. Los resultados muestran como los caminos seguidos por los inmigrantes para la formación de la pareja difieren sobre todo en función de la edad en el momento de migrar, del sexo y del lugar de origen. Si se controla por edad en el momento de migrar y otras características sociodemográficas, las mujeres tienen mayor tendencia que los hombres a estar emparejadas cuando migran y a participar en migraciones relacionadas con motivos familiares. Los inmigrantes africanos son los que muestran mayores diferencias entre los patrones migratorios familiares de hombres y mujeres. Sin embargo, en el caso de los europeos y de los latinoamericanos, estas diferencias son casi inexistentes. Las diferencias por región de origen aparecen sobre todo cuando se examinan las probabilidades de migración conjunta y la migración por reagrupamiento del segundo miembro de la pareja.

Palabras clave: migración internacional; nupcialidad; familia; España.

1. Los autores quieren expresar su agradecimiento a los evaluadores anónimos por sus recomendaciones. Este trabajo se emmarca en el proyecto I+D El impacto de la población extranjera en la formación de la pareja en España, Plan I+D 2004-2007 (SEJ2007-60014/SOCI). Albert Esteve es investigador Ramón y Cajal. Clara Cortina es miembro del Grupo de Estudios sobre Población y Sociedad (GEPS). Ambos son miembros del Grup de Recerca en Demografia i Famílies (DEMFAMS). 
Resum. Trajectòries conjugals dels immigrants internacionals a Espanya

Estudis recents mostren la importància de la dimensió familiar per comprendre els patrons migratoris actuals, així com per reforçar els vincles familiars transnacionals. Malgrat tot, és necessari realitzar anàlisis quantitatives de la situació a la llar dels immigrants internacionals en el moment d'arribar a Espanya i també més tard. En aquest article, s'hi analitza la formació de parelles i s'hi proposa un marc a través del qual es poden classificar els itineraris seguits per immigrants que viuen a Espanya, segons el seu estatus conjugal abans de la migració, durant i després. S’hi utilitzen regressions logístiques per analitzar les dades de la Encuesta Nacional de Inmigración de 2007 sobre 15.384 immigrants. Els resultats mostren com els itineraris seguits pels immigrants en la formació de la parella difereixen sobretot en funció de l'edat en el moment de migrar, el sexe i el lloc d'origen. Si es controla per edat en el moment de migrar i altres característiques sociodemogràfiques, les dones tenen més tendència que els homes a estar emparellades quan migren i a participar en migracions relacionades amb motius familiars. Els immigrants africans són els que mostren més diferències entre els models migratoris familiars d'homes i dones. Malgrat tot, en el cas dels europeus i dels llatinoamericans, aquestes diferències són gairebé inexistents. Les diferències per regió d'origen apareixen principalment quan s'examinen les probabilitats de migració conjunta i la migració per reagrupament del segon membre de la parella.

Paraules clau: migració internacional; nupcialitat; família; Espanya.

\section{Résumé. Chemins vers la formation des familles chez les immigrants en Espagne}

De récentes recherches ont montré l'importance de la dimension familiale dans la compréhension des modèles migratoires contemporains et dans le renforcement des nouveaux liens familiaux transnationaux. Cependant la situation familiale des migrants internationaux au moment de leur arrivée est un phénomène peu exploré en Espagne. Cet article analyse la formation des couples de migrants et propose une classification des trajectoires migratoires et conjugales. On utilise des techniques de régression logistique pour analyser l'échantillon de 15.384 migrants internationaux recensés par l'Enquête Nationale sur l'Immigration de 2007. Les résultats montrent que les trajectoires migratoires et conjugales different surtout en fonction des âges au moment de la migration, du sexe et du pays d'origine des migrants. Si on élimine l'effet de l'âge au moment de la migration et d'autres caractéristiques sociodémographiques, on constate que les femmes sont plus susceptibles que les hommes à migrer quand elles sont déjà en couple et à participer à des projets de migration familiale. Cet écart entre les sexes est particulièrement marquée dans le cas de l'Afrique et au contraire presque imperceptible au sien des populations européennes ou latino-américaines. Les résultats indiquent également qu'il existe des différences significatives entre pays d'origine en ce qui concerne la probabilité d'un regroupement familial (du second conjoint) ou d'une migration en couple.

Mots clé: migration internationale; mariage; famille; Espagne.

\section{Abstract. Pathways to family formation of international migrants in Spain}

Recent research has stressed the importance of families in understanding contemporary patterns of international migration and the strengthening of transnational family bonds. In spite of this, there is a need for a quantitative assessment of the family circumstances upon entry and after arrival. In this paper, we analyze union formation and propose a framework of the pathways in which migrants in Spain are classified according to their union status before, during and after migration. Logistic regression is used 
to analyze data from the National Immigration Survey (2007) for 15,384 international migrants. Results show that age at migration, sex and origin account for most differences in migrants' pathways to union formation. When controlling for age at migration and other socioeconomic traits, women are more likely than men to be in union at the time of migration and to take part in a family-related migration. African immigrants show the highest differences between men and women in family migration patterns while there are almost no differences by sex among Latin Americans and Europeans. Differences by region of origin appear when examining the likelihoods of joint migration and second spouse regrouping.

Key words: international migration; marriage; family; Spain.

\begin{aligned} & \multicolumn{2}{c}{ Sumario } \\ & Introducción Resultados \\ & Migración y familia Conclusiones \\ & La migración internacional en España Referencias bibliográficas \\ & Datos y métodos Anexo \end{aligned}

\section{Introducción}

La migración tiene un perfil por edades bien definido. Las tasas de migración más elevadas se concentran en las edades jóvenes adultas y, a mayor distancia, en las edades infantiles y en las avanzadas cercanas al fin de la vida laboral (Rogers, 1988; Rogers, Raquillet, Castro, 1978). La mayoría de los flujos inmigratorios, por tanto, están protagonizados por individuos en unas edades en las cuales la decisión de migrar coincide o es cercana en el tiempo con otras decisiones o eventos en la vida de éstos, tales como la finalización de los estudios, la obtención del primer trabajo, la formación de pareja o el tener hijos. Por definición, son edades con una elevada heterogeneidad interna a las que la decisión de migrar añade, si cabe, aún más diversidad; por ejemplo: la migración puede retrasar el comienzo de una relación de pareja, separar padres de hijos o unir familias mediante un proceso de reunificación. La tendencia dominante a considerar la migración como un fenómeno meramente individual ha ocultado, en parte, la diversidad de situaciones de pareja y de familia en las que se encuentran los migrantes. Este hecho, junto con la escasez de datos, es responsable de la ausencia de trabajos empíricos que aporten luz sobre estos aspectos. Ausencia que contrasta con el reconocimiento creciente del papel que las estructuras transnacionales y las redes familiares tienen en la integración y adaptación de los inmigrantes en la sociedad de destino.

Por estos motivos, en este trabajo, nos proponemos investigar las características de los migrantes en relación con su situación de pareja. Para ello, analizamos la experiencia reciente de España con datos de la Encuesta Nacio- 
nal de Inmigrantes de 2007. En primer lugar, identificamos las trayectorias de migración y de pareja de los principales orígenes de la inmigración internacional en España y, en segundo lugar, comparamos la diversidad entre los grupos controlando las características individuales de los migrantes. España constituye un excelente banco de pruebas, al ser, junto a los Estados Unidos, uno de los países del mundo que más inmigración internacional ha recibido en la última década (OCDE, 2008), pero que, a diferencia de los Estados Unidos, es un país de escasa experiencia inmigratoria antes de la década de 1990 (Arango, 2004). La llegada masiva de inmigrantes internacionales ha supuesto una fuente importante de heterogeneización cultural, racial y étnica de la población española, todavía hoy dominada por el peso de las primeras generaciones de migrantes.

Este artículo se estructura en cinco apartados. Primero, argumentamos la necesidad de entender el fenómeno migratorio desde una perspectiva integrada, que incluya la dimensión familiar para comprender aspectos tan importantes como la existencia de redes transnacionales o la integración de los inmigrantes en el país de destino. En este primer apartado, proponemos un esquema conceptual para identificar las trayectorias que resultan de la interacción entre migración y formación de la pareja. Segundo, realizamos una breve presentación de la experiencia inmigratoria de España en los últimos diez años para situar al lector en la importancia de este fenómeno en cuanto a su intensidad, aceleración y diversidad de orígenes. En el tercer apartado, describimos detalladamente la fuente de los datos, la Encuesta Nacional de Inmigrantes, y el proceso de construcción de las trayectorias a partir de las variables proporcionadas en esta encuesta. En el cuarto y quinto apartados, presentamos y valoramos los resultados, respectivamente.

\section{Migración y familia}

La dimensión familiar es un elemento indispensable para entender tanto los motivos de la migración como la integración de los migrantes en la sociedad de destino. La influencia que ha ejercido la migración laboral sobre el estudio de las migraciones ha relegado el papel de la familia a un alejado segundo plano. Sin embargo, en décadas recientes, la diversidad creciente de los tipos de migración internacional y los desarrollos teóricos que explícitamente incorporan la dimensión familiar están erosionando esta visión excesivamente individual y económica de la migración internacional (Kofman, 2004).

A nivel teórico, a las motivaciones individuales para emprender un proyecto migratorio, hay que añadir las que se derivan del entorno familiar del migrante. En la década de 1980, la teoría de la nueva economía de la migración laboral reconoció la importancia de los miembros del hogar en la decisión de migrar (Stark, Bloom, 1985), por ejemplo, a la hora de calcular los costes y los beneficios para la unidad familiar de la migración de unos de sus miembros. La situación familiar de los migrantes ha resultado, pues, ser una variable que ha contribuido a entender mejor las causas de la migración (Borjas, Bronars, 
1991). El carácter predominantemente familiar de las redes migratorias y la importancia de éstas en los procesos de migración confiere a la familia un lugar de excepción en el entramado teórico y conceptual de las teorías actuales de la migración (Massey, 1987; Boyd, 1989; Palloni et al., 2001; Smith, 2004; Cooke, 2008).

A nivel empírico, la diversificación de los tipos de migración que caracterizan a las sociedades actuales ha sido en parte generada por el aumento continuado de la migración de tipo familiar, cada vez más importante, hasta convertirse en la vía de entrada legal más común en los países desarrollados. Detrás de este aumento, están las crecientes restricciones a la entrada legal de flujos por razones laborales (Kofman, 2004; Strasser et al., 2009).

La dimensión familiar no es sólo necesaria para entender las motivaciones o las causas de la migración, sino también para comprender mejor su adaptación o su estrategia en la sociedad de destino, en la medida que esta situación seguirá ejerciendo, en mayor o menor grado, cierta influencia sobre el individuo. El desarrollo de las tecnologías de la comunicación y la reducción del coste de los viajes relativiza el concepto de distancia y permite la consolidación de redes transnacionales a unos niveles no conocidos anteriormente. Así, la existencia de estas redes condiciona diversos aspectos de la vida del migrante, desde su participación en el mercado de trabajo hasta su estrategia familiar (Boyle, Feng y Gayle, 2009).

En el ámbito laboral, un ejemplo lo constituyen los trabajos realizados en Estados Unidos, que han mostrado que los inmigrantes que tienen un proyecto individual están más seleccionados en sus aptitudes y en sus potencialidades laborales que los que lo hacen en el marco de una estrategia familiar, en la que de lo que se trata es de maximizar los ingresos comunes y no los individuales (Borjas y Bronars, 1991). Otros resultados señalan que esta teoría de la menor selección se vería especialmente confirmada para el caso específico de las mujeres en países como Alemania (González-Ferrer, 2008).

A nivel familiar, aunque mucho menos estudiado, los vínculos con la familia de origen pueden influir en el comportamiento familiar del migrante. Junto con las características individuales de los migrantes y su situación legal, el hecho de haber llegado solos, como cabecillas de un proyecto de migración familiar, o bien vía reagrupación, son aspectos que determinan su participación en el mercado matrimonial del país de destino, sus pautas de fecundidad o la composición de sus hogares. Es abundante la literatura que investiga las singularidades de los comportamientos familiares de los migrantes, tanto en lo que se refiere a sus niveles de endogamia, como a sus diferenciales de fecundidad o la complejidad de los hogares (Carlson, 1985; Pagnini y Morgan, 1990; Blank y Torrecilha, 1998; Andersson, 2004; Vila y Castro-Martín, 2007). Sin embargo, es menos abundante la que vincula estas singularidades con la condición y la trayectoria migratoria de los migrantes (Dinkel y Lebok, 1997; Van Hook y Glick, 2007). Normalmente, las diferencias entre colectivos e individuos se atribuyen a factores culturales, de preferencia a las condiciones socioeconómicas o a la selección de los migrantes (Kahn, 1988). 
Delimitada brevemente la importancia de las redes y la situación familiar de los migrantes en su decisión de migrar y en su posterior integración en la sociedad de destino, precisaremos con más detalle los objetivos específicos que guían el presente trabajo. Primero, de la circunstancia familiar de los migrantes, nos centramos en un aspecto muy concreto: su situación de pareja. En este caso, adoptamos una definición muy restrictiva de familia que limitamos exclusivamente a tener o no tener pareja. Una definición que facilita el análisis y que constituye un buen punto de partida para entender la diversidad familiar de los migrantes. No pretendemos investigar directamente las motivaciones de la migración ni analizar el comportamiento diferencial de los migrantes en la sociedad de destino en función de su situación familiar. Simplemente, queremos ilustrar en qué situación de pareja se encuentran los migrantes antes, en el momento y después de la migración. El objetivo es doble. Primero, conocer la diversidad familiar de los migrantes en su conjunto: tienen o no tienen pareja en el momento de migrar, migran junto a sus parejas, reagrupan o no reagrupan, forman o no forman pareja en el país de destino. Segundo, estudiar las diferencias por sexo y entre colectivos, puesto que esperamos encontrar perfiles bien diferenciados. En concreto, examinamos las diferencias entre colectivos de distinto origen, representativos de la inmigración internacional en España $\mathrm{y}$ con situaciones legales distintas en cuanto a sus posibilidades de establecer residencia en este país.

Antes de proceder a la presentación de los resultados, a continuación desarrollamos una propuesta conceptual para identificar las principales trayectorias de migración y pareja de los migrantes internacionales. La relación que se establece entre el proceso migratorio y la formación de la pareja es compleja y puede dar lugar a una diversidad de trayectorias cuando se relacionan entre sí. Una trayectoria es el curso que, a lo largo del tiempo, sigue el comportamiento o el estatus de una persona. La ordenación en el tiempo de los cambios en el comportamiento o en el estatus de una persona da lugar a una secuencia. Para establecer una secuencia, es necesario conocer el orden temporal de los eventos o cambios que la originan, pero no es necesario, aunque sí deseable, conocer la fecha exacta de los eventos y la duración entre ellos. Disponer de fechas exactas nos da una aproximación más precisa de las trayectorias y permite conocer el intervalo temporal que hay entre un estado y otro y, por tanto, considerar la duración como un factor del cambio, pero, en cualquier caso, sin duraciones también pueden reconstruirse las trayectorias, siempre que podamos establecer una secuencia ordenada temporalmente. En nuestro esquema, utilizamos el concepto de pathways como una secuencia de eventos, en un sentido similar al que lo usan Massey y Malone (2002) para estudiar las vías de acceso a la regularización de los inmigrantes internacionales en Estados Unidos. En nuestro caso, sin embargo, lo utilizamos para explorar la interacción entre el proceso migratorio y el de formación de pareja.

Desde una óptica transversal y en relación con su situación conyugal, una persona puede tener pareja o no tenerla. Estos últimos pueden clasificarse en dos categorías según residan o no con su pareja, una clasificación necesaria en 
los colectivos de inmigrantes, ya que la proporción de éstos que no conviven con su pareja es mayor que la del conjunto de la población, como consecuencia de las separaciones impuestas por la migración. Los individuos que están en pareja, pueden estarlo por primera vez o bien haberlo estado en otras ocasiones. Los individuos que no lo están, pueden haberlo estado anteriormente y haberse separado, divorciado o enviudado. Nos interesa conocer la situación conyugal del inmigrante antes, en el momento y después de la migración.

Como muestra la figura 1 , un inmigrante, antes de migrar, puede estar sin pareja, con pareja residiendo con ella o con pareja sin residir con ella. En este último caso, se encontrarían todos aquellos individuos cuya pareja vive en otro país y que probablemente migró con anterioridad (aunque también podría ser una pareja no migrante). En el momento de la migración, los individuos que no tienen pareja llegan sin pareja al país de destino. Los que tienen pareja y conviven con ella en el país de origen, pueden migrar junto a su pareja, con lo cual mantienen el mismo estatus en el país de destino, o pueden migrar sin su pareja. En este caso, el migrante pasaría de residir con su pareja en el país de origen a no hacerlo en el país de destino. Finalmente, los que tienen pareja y no conviven con ella en el país de origen, migran solos, pero su situación en el país de destino varía si se trata de una reagrupación conyugal. En este caso, pasarían a residir junto a su pareja.

En el país de destino, la situación de los inmigrantes puede variar en múltiples direcciones. Los migrantes que llegaron solos pueden emparejarse. Algunos de ellos se emparejarán y residirán con sus parejas. Otros se emparejarán pero no residirán con sus parejas. Los que llegaron con su pareja pueden romper su relación y aumentar la cifra de los que no están unidos. En buena medida, el

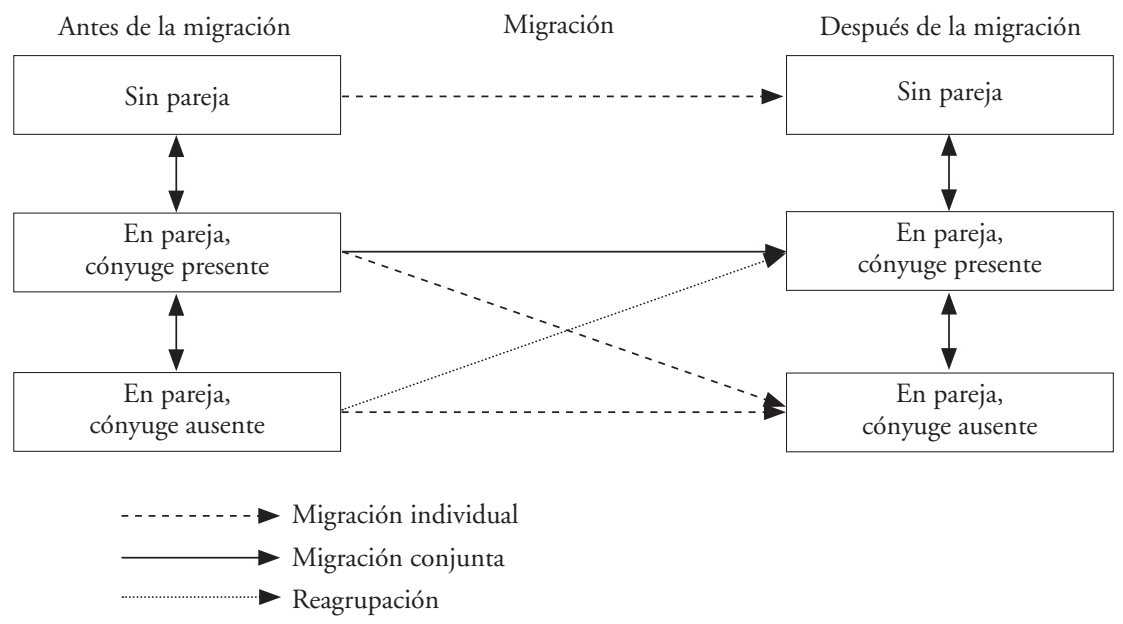

Figura 1. Diagrama de las trayectorias conyugales y migratorias. 
riesgo de ruptura puede estar determinado por la misma migración y la separación posterior, lo cual demuestra que la relación entre migración y pareja es bidireccional. Por último, los que, teniendo pareja, llegaron sin ella pueden reagrupar a sus parejas con posterioridad.

De la situación de pareja en cada uno de los momentos de la migración, se deriva un gran número de trayectorias posibles, unas más frecuentes que otras. En buena medida, estas trayectorias dependerán de características demográficas básicas de los migrantes. En primer lugar, la edad en el momento de la llegada, puesto que la probabilidad de tener o no tener pareja no es independiente de la edad de las personas. Tampoco lo es el nivel de estudios. Las diferencias por sexo dependerán del tipo de migración que estemos analizando. Así, es lógico esperar que, en los colectivos más masculinizados, los hombres llegarán sin pareja en una proporción mayor a las mujeres de su mismo origen. La situación contraria se observará cuando estos colectivos estén feminizados. A estas diferencias, hay que añadir la variación entre colectivos. La procedencia de estos colectivos, los motivos de la migración, su situación legal y el perfil socioeconómico de sus miembros condicionarán las posibles trayectorias. Podríamos anticipar algunas de estas diferencias para el caso español a modo de hipótesis, pero hemos preferido, en esta sección, mantener el carácter general de nuestra propuesta de clasificación y, a continuación, dar algunas cifras sobre la inmigración internacional en España.

\section{La migración internacional en España}

Según el padrón de población ${ }^{2}$ de 1 de enero de 2008, el 13,1\% de los poco más de 46 millones de habitantes que tenía España en esta fecha había nacido en el extranjero (ver figura 2), es decir, aproximadamente 6 millones, de los cuales el 85\% eran de nacionalidad extranjera. Diez años antes, en 1998, residían en España 1,2 millones de extranjeros. Esto nos da un crecimiento de la población nacida en el extranjero de casi 5 millones de habitantes en tan sólo diez años. Un crecimiento sin parangón en la historia de este país y por encima de los crecimientos experimentados en la misma época por otros países desarrollados (OCDE). El aumento de la población extranjera es el resultado de la intensificación de los flujos de inmigración internacional desde mediados de los años noventa y va acompañada de una diversificación de las procedencias de estos flujos (Arango, 2004; Domingo y Gil, 2007). La velocidad con la que la inmigración ha transformado la fisonomía demográfica y social de España es una singularidad del caso español en relación con otros países desarrollados (González-Ferrer y Cebolla, 2008).

Según los datos más recientes del padrón (ver figura 2), los tres colectivos más numerosos son, por este orden, Rumania, con 706.164 personas; Marruecos, con 683.102, y Ecuador, con 458.437. Los rumanos, además de

2. El padrón de población es una fuente de registro municipal continuo de los habitantes que ofrece las cifras oficiales de población en España. 
los más numerosos, son el colectivo más reciente. Por el contrario, la población marroquí tiene una presencia en España que se remonta a mediados de los años setenta (Aparicio, 2005). Por grandes grupos, la inmigración latinoamericana representa, en 2008, cerca del 40\% (incluyendo a Ecuador) de la inmigración total y la de la Unión Europea, una cifra similar (incluyendo Rumanía). Aunque no mostramos los datos desagregados por sexo, es importante resaltar los desequilibrios por sexo en función del colectivo. Africanos y latinoamericanos presentan en su conjunto diferencias por sexo notables. En el primer caso, el número de hombres excede el de mujeres, mientras que en el segundo ocurre lo contrario. Este desequilibrio, sumado a una estructura concentrada en edades jóvenes, caracteriza demográficamente a estos colectivos, lo cual muestra el perfil propio de las poblaciones migrantes observadas a pocos años de su llegada (Cortina, Esteve y Domingo, 2008).

En cuanto a su situación legal, los colectivos examinados presentan importantes diferencias entre sí. Hay que tener en cuenta que la inmigración internacional en España se ha caracterizado por unos elevados niveles de irregularidad, tanto en las entradas como en la residencia (González-Ferrer y Cebolla, 2008). Esto no afecta a los ciudadanos de la Unión Europea, que pueden entrar, salir y residir en España legalmente sin necesidad de visado. Para el resto de los orígenes, son necesarios permisos de entrada y de residencia; sin embargo, existen condiciones más favorables para acceder a la nacionalidad española por residencia para algunos países, concretamente los países latinoamericanos, Andorra, Guinea Ecuatorial, Filipinas y Portugal (así como para los inmigrantes que consiguieron estatuto de asilado o refugiado).

El crecimiento de la población extranjera en España se refleja también en fenómenos demográficos como la fecundidad o la nupcialidad, tal y como

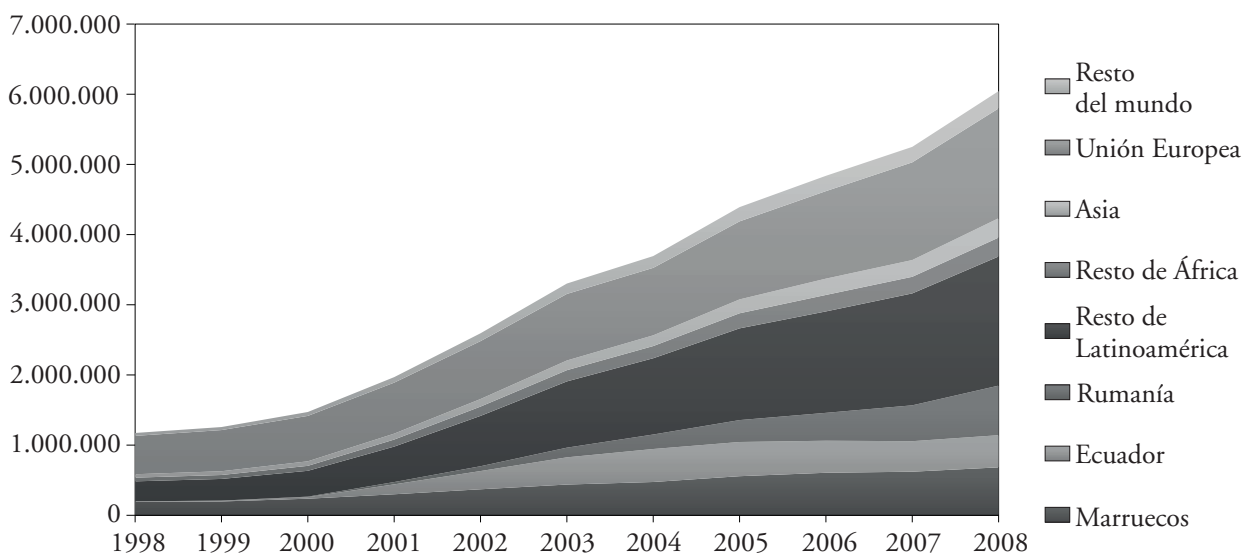

Figura 2. Evolución de la población nacida fuera de España según país de nacimiento (1998-2008). Fuente: Padrón Municipal de Población, INE, elaboración propia. 
muestran los registros vitales: el porcentaje de nacimientos en los que al menos uno de los progenitores es extranjero ha pasado de 4,5\% en 1997 a 24,2\% en 2009. En el mismo periodo, el porcentaje de matrimonios que implican a por lo menos un cónyuge extranjero ha pasado de $4,6 \%$ a $20,9 \%$. Sin embargo, trabajos anteriores han mostrado la escasa representatividad de las uniones de extranjeros que aparecen en el registro de matrimonios, la mayoría de las cuales están constituidas por parejas mixtas entre un extranjero y un español, cuando, al comparar con otras fuentes, observamos que la mayoría de ellos están unidos con personas del mismo origen (Cortina et al., 2009). El hecho de conocer las trayectorias de pareja y migración de estos inmigrantes nos permitirá comprender discrepancias entre fuentes.

\section{Datos y métodos}

Los datos utilizados en esta investigación proceden de la Encuesta Nacional de Inmigrantes, publicada por el Instituto Nacional de Estadística y realizada entre noviembre de 2006 y febrero de 2007. Se trata de una encuesta con información retrospectiva basada en una muestra de 15.465 personas nacidas en el extranjero de 16 años o más en el momento de la encuesta que llevan residiendo en España al menos un año o, no siendo así, que tienen intención de residir en el país al menos un año. Los nacidos fuera con nacionalidad española de nacimiento que llegaron a España antes de cumplir los dos años de edad quedaron excluidos del ámbito poblacional de la encuesta (Reher y Requena, 2009). Para los individuos entrevistados, la encuesta proporciona información de sus características sociodemográficas, experiencia migratoria, condiciones en el país de partida, llegada a España, historia laboral y residencial, relación con el país de nacimiento, participación social y situación documental. Adicionalmente, tenemos información sobre los miembros con los que comparte vivienda el entrevistado. Esta información se limita al país y a la fecha de nacimiento, al sexo, al año de llegada a España, al país o a los países de nacionalidad, y al año de adquisición de la nacionalidad española, si corresponde. Cuando el esposo o la esposa no convive con el entrevistado, éste último proporciona la información de su pareja. Se trata de las mismas variables que se conocen para los miembros de la vivienda más el lugar de residencia en el momento de realizar la encuesta.

Siguiendo las recomendaciones del Instituto Nacional de Estadística, los resultados se presentan a nivel nacional y para los países de origen más relevantes: Ecuador, Marruecos, Rumanía, Latinoamérica (sin Ecuador), África ( $\sin$ Marruecos ni Sudáfrica), Asia (sin Japón ni Israel), la Unión Europea ampliada (incluyendo a países europeos occidentales no miembros de la Unión de los 27, como Noruega o Suiza, y también a países como Estados Unidos y Australia) y el resto del mundo (que incluye fundamentalmente a países de la Europa oriental). Los tres primeros orígenes son, como hemos visto en la sección anterior, los más numerosos y representan el 30\% de la inmigración internacional en España. 
Conocida la estructura de la encuesta, a continuación explicamos cómo se han construido las trayectorias migratorias y de pareja, que han sido derivadas de la situación de pareja en tres momentos del tiempo: antes de la migración, en el momento de la migración y en el momento de la encuesta. Antes, sin embargo, es preciso aclarar algunos aspectos. En primer lugar, estas trayectorias no tienen duraciones porque los eventos relacionados con la formación de la pareja no están fechados, a excepción del año del último matrimonio. En segundo lugar, desconocemos si han existido cambios de estado en la situación de pareja entre el momento de la migración y el momento de la encuesta, ya que la fuente no proporciona información sobre la historia matrimonial y de parejas estables de los inmigrantes. Así, por ejemplo, si un inmigrante llegó con su pareja a España y convive en el momento de la encuesta con una pareja extranjera que llegó en el mismo año, asumimos que se trata de la misma persona. En tercer lugar, se pueden identificar matrimonios y uniones consensuales, tanto en origen como en destino, si bien sólo conocemos la fecha del matrimonio vigente, y no la del inicio de la unión consensual vigente. Si bien podría resultar interesante distinguirlas, especialmente teniendo en cuenta la desigual incidencia de la cohabitación según los orígenes que la evidencia empírica ha demostrado, las trayectorias que proponemos atribuyen el mismo valor a unas y otras en la secuencia de acontecimientos, lo cual implica renunciar a la fecha de inicio de la unión.

A pesar de estas limitaciones, las trayectorias que proponemos satisfacen sobradamente los objetivos de nuestra investigación. Siguiendo el esquema conceptual propuesto en la primera sección, el inmigrante en el país de origen puede estar en estos tres estados: (1) sin pareja; (2) con pareja, cónyuge presente, o (3) con pareja, cónyuge ausente. Los dos primeros estados son inferidos directamente de la siguiente pregunta: «¿Dónde vivía su pareja en el momento de llegar a España?». Las personas que respondieron «no tiene pareja» a esta pregunta son consideradas sin pareja. Esta categoría incluye a solteros, separados, divorciados y viudos que declararon no tener pareja en el momento de llegar a España, pero no podemos diferenciarlos por estado civil, porque no conocemos este dato antes de la migración, ni tampoco el historial matrimonial o de pareja de los inmigrantes antes de llegar a España. A las personas que declararon tener pareja en el mismo hogar, las consideramos con pareja, cónyuge presente. Y las personas que tenían a su pareja fuera del país las consideramos con pareja, cónyuge ausente. En una proporción reducida de casos $(3,9 \%)$, la pareja del inmigrante no residía ni en el mismo hogar ni fuera del país, sino en el mismo país pero en distinta vivienda, la gran mayoría, en el mismo municipio (64.3\%). Hemos asignado estos casos a la categoría con pareja, cónyuge presente.

En una segunda fase, nos interesamos por la posición de la pareja en el momento de la migración y sólo para aquellas que, obviamente, tenían pareja antes de llegar a España. En concreto, distinguimos si la persona migró junto a su pareja o en solitario y, en este último caso, diferenciamos entre si migró en primer lugar o en segundo lugar. Para construir esta información, utilizamos las respuestas a dos preguntas de la encuesta: «¿En qué año llegó a España?», 
pregunta realizada a ambos cónyuges, y «¿Con quién se trasladó a este país?». Si los dos cónyuges llegaron el mismo año y el entrevistado responde que se desplazó con toda su familia o con parte de ella, consideramos que se trata de una migración conjunta. Si el inmigrante declara que llegó solo aún teniendo pareja, pero su pareja llegó en el mismo año, hemos considerado que se trata también de una migración conjunta, puesto que la separación, de muy corta duración, puede ser considerada como logística o técnica. Entre los que migraron sin su pareja, distinguimos dos situaciones. Aquellos que migraron en primer lugar dejando a su pareja en el país de origen y aquellos que llegaron a España teniendo a su pareja en este país. En la primera situación, se encuentran los inmigrantes que llegaron solos a España o con algún familiar que no incluye a su pareja, puesto que no coinciden los años de llegada o porque ésta reside todavía en el país de origen. En la segunda situación, se encuentran las personas que migraron solas a España para reencontrarse con sus parejas (mediante un proceso de reagrupación familiar por vía legal o no), porque declararon que su pareja residía en España en el momento de la llegada al país.

La figura 3 muestra, para hombres y mujeres respectivamente, la situación de pareja en el momento de llegar a España por edad en el momento de migrar. En ella, se observan la diversidad de situaciones de pareja en las que los inmigrantes se encuentran en el momento de la migración y las diferencias por edad en el momento de emigrar y entre sexos. La proporción de hombres y mujeres que no tienen pareja en el momento de la migración disminuye claramente con la edad. Aunque son la mayoría, no se trata exclusivamente de personas solteras. Como no conocemos el estado civil a la edad de llegada, no podemos distinguir entre solteros y alguna vez casados. Sí que podemos utilizar el estado civil actual para explicar las diferencias entre hombres y mujeres a edades avanzadas. La soltería es un estado irreversible al que no se puede retornar una vez casado. Gracias a esto, sabemos que la gran mayoría de hombres y mujeres que llegaron sin pareja y no tienen pareja en el momento de la encuesta son, y por tanto eran, solteros (un 92,9\% entre los hombres y un 72,9\% entre las mujeres). El peso de los separados, divorciados y viudos aumenta con la edad de llegada, muy especialmente entre las mujeres.

La proporción de hombres y de mujeres que llegan con su pareja aumenta con la edad, aunque no es la pauta mayoritaria hasta la franja de 45-49 años. A partir de esta edad, los inmigrantes que llegan con pareja lo hacen básicamente de forma conjunta. Antes de esta edad, sin embargo, la opción mayoritaria entre los hombres que tienen pareja es llegar solos y en primer lugar. El perfil migratorio de las mujeres que tienen pareja es distinto al de los hombres. Entre los 15 y los 45 años, el porcentaje de mujeres reagrupadas oscila entre el 6\% y el $11 \%$, mientras que para los hombres es muy inferior, siempre por debajo del $4 \%$. En cambio, el porcentaje de mujeres que migran solas en primer lugar y cuyas parejas se quedan en el país de origen, es menor que el de los hombres y a ninguna edad alcanza el $20 \%$.

Para completar el proceso de construcción de las trayectorias de migración y pareja de los inmigrantes, nos queda por incorporar su situación actual según 
se encuentre en uno de estos tres estados: (1) sin pareja; (2) con pareja, cónyuge presente, o (3) con pareja, cónyuge ausente. La situación de pareja actual viene determinada por la presencia o la ausencia de un cónyuge entre los miembros de la vivienda, información que derivamos de las relaciones de parentesco entre la persona entrevistada y el resto de miembros del hogar. Los que no tienen cónyuge en la vivienda pero sabemos que está ausente gracias a una pregunta que se realiza directamente al entrevistado, son considerados con pareja, cónyuge ausente. El resto son sin pareja.

Hombres

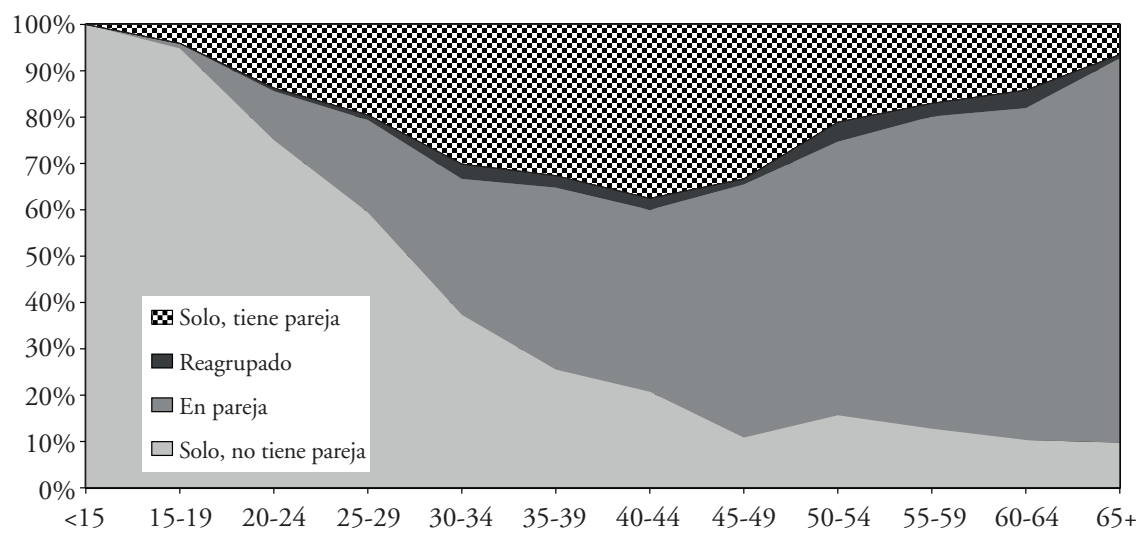

Mujeres

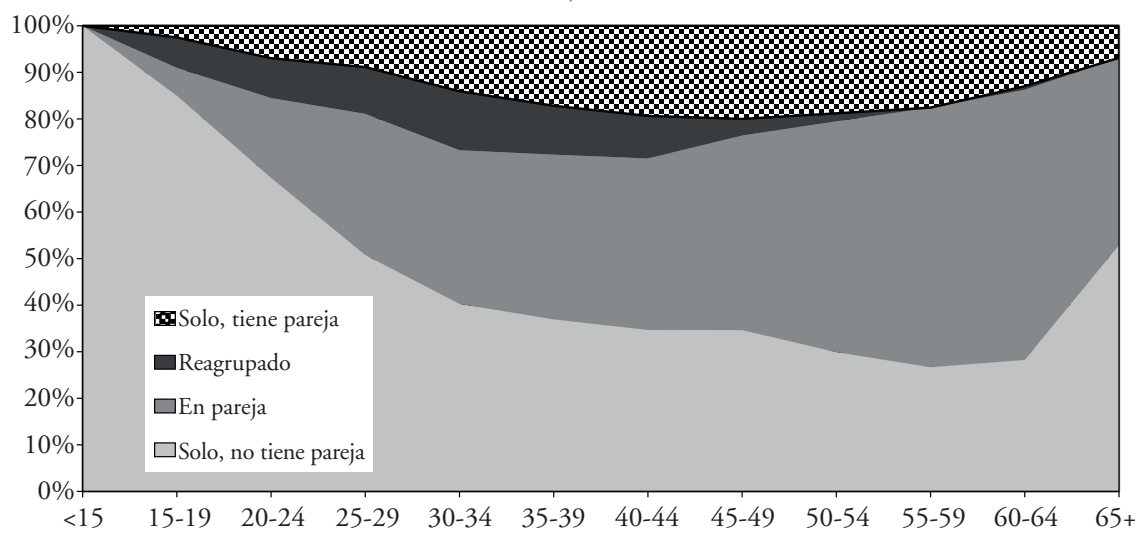

Figura 3. Distribución de los inmigrantes según edad y situación de pareja a la llegada a España, por sexo.

Fuente: Encuesta Nacional de Inmigrantes, INE, elaboración propia. 
Combinando los tres momentos, se obtienen seis trayectorias identificadas más un grupo final de otros. Las seis trayectorias son:

1. Individuo que no tenía pareja en el momento de llegar y sigue sin tener pareja en el momento de la encuesta $(28,7 \%)$.

2. Individuo que no tenía pareja en el momento de llegar y tiene pareja en el momento de la encuesta (26,4\%). Son personas que se han emparejado después de haber llegado a España, tanto aquí como en su país de origen, en cuyo caso estaríamos hablando de aquellos casos que, en la literatura, suelen denominarse «importadores» del cónyuge.

3 . Individuo que migró con su pareja y tiene una en el momento de la encuesta $(20,5 \%)$.

4. Individuo que tenía la pareja en España en el momento de la migración y reside con ella en España (3,8\%). Esta categoría incluye a las personas que llegaron a España más tarde que sus cónyuges y, por tanto, también incluye a las personas reagrupadas mediante un proceso de reunificación familiar.

5. Individuo que tenía pareja en el país de origen antes de llegar a España, migró en solitario pero ahora reside actualmente con ella aquí (6,3\%).

6. Individuo que tenía y tiene pareja, migró solo y no reside con su pareja en España $(6,0 \%)$.

7. Otras $(7,4 \%)^{3}$.

En la sección de resultados, presentamos, en primer lugar, la distribución de las trayectorias entre colectivos y por sexo. Para comparar los colectivos entre sí y por sexo, utilizamos la regresión logística. Esta técnica nos permite introducir variables de control que pueden explicar parte de las diferencias entre grupos. Junto al sexo y el origen, los modelos incluyen, como variables de control, la edad de llegada, la edad de llegada al cuadrado, la educación y el año de llegada reunido en cuatro grandes grupos (antes de 1970, en 1970-1979, en 1980-1995 y en 1996-2007), los años de residencia y los años de residencia al cuadrado ${ }^{4}$. Las variables de control se han introducido como variables numéricas en los modelos (ver tabla en anexo). Para facilitar la comparación entre colectivos, hemos calculado probabilidades por sexo y origen a partir de los coeficientes que nos proporciona el modelo. Esto nos obliga a fijar un perfil de migrante en función del resto de variables incluidas

3. La categoría «otras» incluye diversas trayectorias. Por su escasa representatividad, hemos optado por no mostrarlas por separado, porque nunca superan el $2 \%$ de los casos. En algunas circunstancias, son trayectorias sencillas de reconstruir, en otras, son de reconstrucción más difícil. Por ejemplo, las personas que llegaron con sus parejas y ahora no están en unión se encuentran en este grupo (un 1,4\%). También lo están las personas que no tenían pareja en el momento de llegar, se casaron después pero ya no residen con sus parejas. En otros casos, suponemos que ha habido rupturas y segundas uniones, pero no podemos confirmarlo.

4. Se incluyen las variables de control «edad de llegada» y "años de residencia» al cuadrado porque asumimos que la relación existente entre las distintas variables dependientes y estas variables no es lineal. 
en el análisis. En una regresión de tipo logístico, la probabilidad resulta de la siguiente expresión:

$$
Y=\frac{e^{a+b_{1} X_{1}+b_{2} X_{2} \cdots+b_{\mathrm{n}} X_{\mathrm{n}}}}{1+e^{a+b_{1} X_{1}+b_{2} X_{2} \ldots+b_{\mathrm{n}} X_{\mathrm{n}}}}
$$

Donde la probabilidad de experimentar el evento $(Y)$, es igual a la exponencial constante $(e=2.7183)$ elevada a un exponente. Este exponente equivale a una ecuación clásica de regresión que incluye la constante $(a)$ y todas las variables explicativas incluidas en el modelo $(X)$ multiplicadas por sus coeficientes respectivos $(b)$.

\section{Resultados}

\section{Variación de las trayectorias según sexo y origen}

La tabla 1 presenta la distribución de los hombres y las mujeres inmigrantes de cada país o región de origen según sea su trayectoria combinada de migración y formación de pareja. Los individuos cuyas trayectorias se representan en esta tabla tenían 16 años o más en el momento en que se realizó la encuesta, pero pudieron haber llegado a cualquier edad. Esto explica que, en términos generales, la mayoría de los inmigrantes llegaron a España sin pareja: aproximadamente el $55 \%$, tanto en hombres como en mujeres, si sumamos los que siguen sin tener pareja y los que ya están unidos.

Una cuarta parte de los hombres $(25,5 \%)$ y de las mujeres $(27,3 \%)$ han llegado a España sin tener pareja, pero estaban unidos en el momento de la encuesta; esto equivale a prácticamente la mitad de los que no tenían pareja en el momento de llegar. El resto de trayectorias corresponden a los que tenían pareja en el momento de la llegada. Una quinta parte de los migrantes migró junto a su pareja en el momento de llegar y sigue conviviendo con ella. Esta proporción varía en función de los colectivos. Los europeos son los que tienen las proporciones más elevadas (32,9\% de hombres y $29,5 \%$ de mujeres), mientras que los marroquíes tienen los valores más bajos $(2,9 \%$ de hombres y $9,6 \%$ de mujeres).

Las proporciones de mujeres reagrupadas son, en todos los colectivos, superiores a las de los hombres. En conjunto, hay un 7,4\% de mujeres que llegaron después que sus maridos por un 1,8\% de los hombres que llegaron más tarde que sus esposas. Las diferencias entre colectivos son notables. Entre los europeos (a excepción de Rumanía), apenas hay diferencias entre hombres y mujeres, mientras que, en el resto de colectivos, hay diferencias muy marcadas. El 22,3\% de las mujeres marroquíes han llegado a España después que sus maridos, mientras que sólo un 1,5\% de las mujeres europeas están en la misma situación. En cambio, las personas que reagrupan son mayoritariamente hombres (un $8,5 \%$ de los hombres y un 2,6\% de las mujeres). Finalmente, cabe destacar la proporción de personas con pareja cuyo cónyuge está ausente. Una situación en la que se encuentran mayoritariamente los hombres (un 8,1\% 


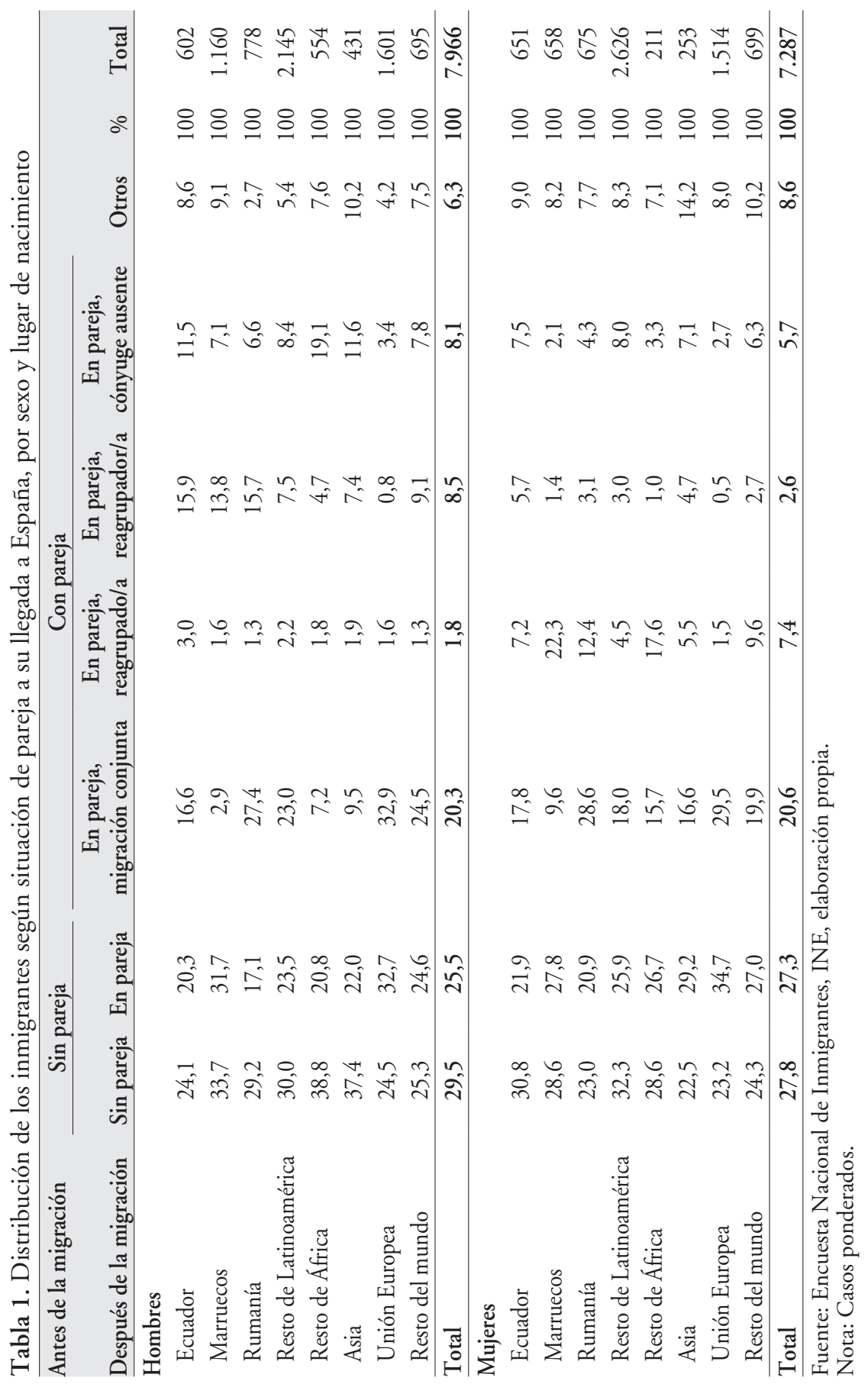


hombres y un 5,6\% mujeres), pero que también muestra diferencias importantes entre colectivos. En este caso, son los hombres africanos (excluyendo Marruecos y Sudáfrica) los que se encuentran con mayor frecuencia en esta situación, prácticamente un 20\% de los hombres que residen en España. Los europeos vuelven a tener las proporciones más bajas (un 3,4\% de hombres y un 2,7\% de mujeres), unas cifras cercanas a las de la población autóctona. Entre las mujeres, destacan las latinoamericanas en su conjunto y las asiáticas, por tener unas proporciones en torno al 7 y el $8 \%$ de mujeres con su pareja ausente.

Para comentar las diferencias entre grupos, preferimos analizar directamente los resultados de la regresión logística, que nos permite introducir variables de control que podrían, en parte, explicar las diferencias observadas en la tabla anterior. En concreto, hemos realizado cuatro modelos. Estos modelos incluyen sexo y origen y unas variables de control que varían en función de la variable dependiente. Como se ha indicado en el apartado anterior, mostramos las probabilidades por sexo y origen para cada una de las variables independientes, tomando como referencia a un individuo tipo que llegó a España con 30 años de edad, tiene estudios secundarios, llegó a España entre 1996 y 2007 y, cuando el modelo incluye años de residencia, lleva cinco años de residencia en España. Lógicamente, si cambiáramos el perfil de nuestro inmigrante tipo, cambiarían en proporción los valores observados, pero se mantendrían inalteradas las diferencias por sexo y colectivo, que son las que nos interesa examinar. A diferencia de la figura 3 , estos modelos sólo consideran a las personas que llegaron entre los 18 y los 49 años de edad.

Las variables analizadas, cuyos resultados se presentan sucesivamente en las figuras 4 a 7, son las siguientes: a) tener pareja en el momento de llegar a España; $b$ ) migrar junto a la pareja en caso de tenerla antes de llegar a España; c) reagrupar a la pareja para los que la tenían antes de llegar a España pero llegaron sin ella; d) formar pareja después de la migración para los que llegaron sin pareja a España.

La figura 4 muestra la probabilidad de tener pareja de un hombre y una mujer de 30 años que llegó a España entre 1996 y 2007, por países de origen. Los resultados muestran que la probabilidad de tener pareja entre las mujeres es más elevada que la de los hombres en todos los colectivos a excepción de los latinoamericanos. Salvo esta excepción, las mujeres llegan dentro de un esquema familiar y de pareja en mayor proporción que los hombres. Las diferencias entre hombres y mujeres no superan los 6 puntos, a excepción de los orígenes africanos. La probabilidad de las mujeres marroquíes de llegar a España teniendo pareja es 16 puntos superior a la de los hombres. Y las del resto de África, en su mayoría subsaharianas, tienen una probabilidad 26 puntos mayor que la de los hombres. Por colectivos, ecuatorianos y rumanos, los dos colectivos más recientes, tienen las probabilidades más elevadas de tener pareja en el momento de llegada, y los europeos las más bajas. Sin embargo, la comparación entre colectivos se ve dificultada por las diferencias entre hombres y mujeres. 


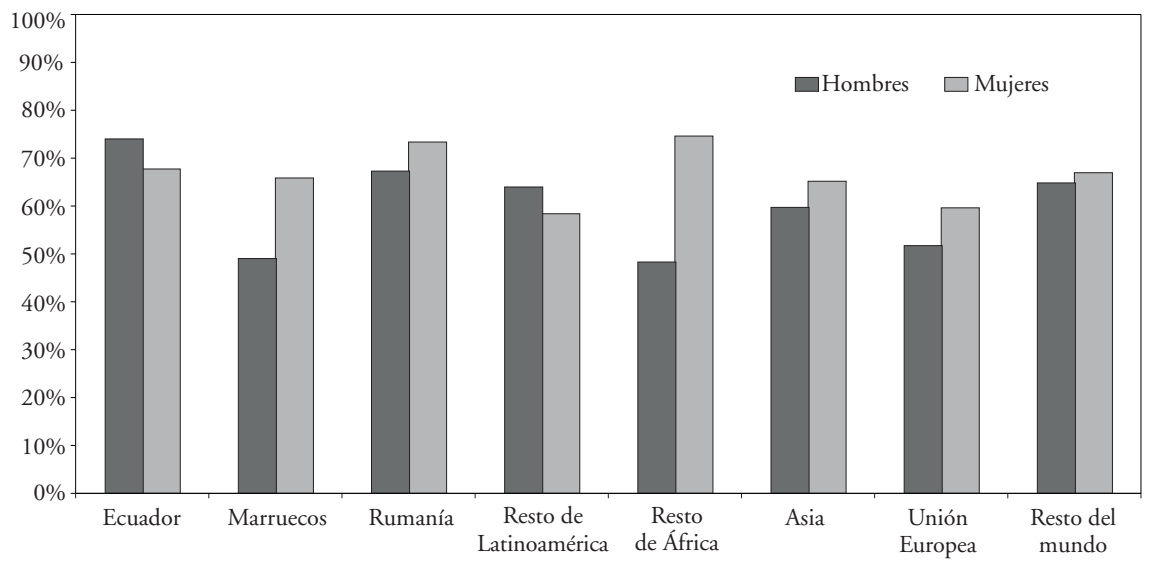

Figura 4. Probabilidad estimada de tener pareja en el momento de migrar, por sexo. Fuente: Elaboración propia.

Nota: Las probabilidades estimadas se han calculado a partir de las odds ratio que se presentan en el anexo y para un individuo tipo (estudios secundarios y que ha llegado a España después de 2006 a los 30 años).

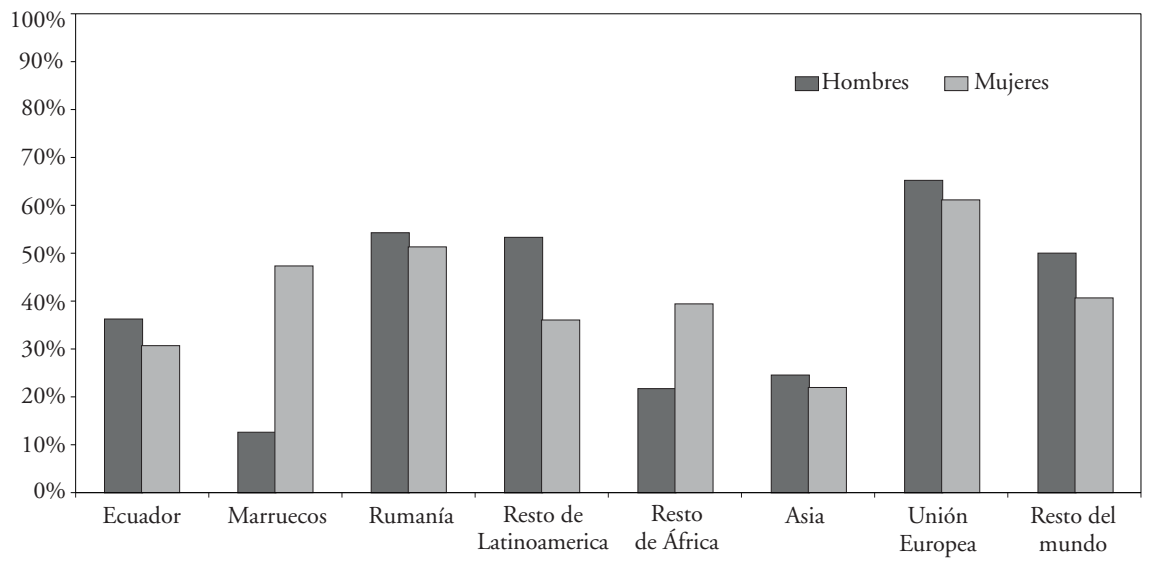

Figura 5. Probabilidad estimada de migrar junto con la pareja (en el caso de tenerla), por sexo. Fuente: Elaboración propia.

Nota: Las probabilidades estimadas se han calculado a partir de las odds ratio que se presentan en el anexo y para un individuo tipo (estudios secundarios y que ha llegado a España después de 2006 a los 30 años). 
La probabilidad estimada de haber migrado conjuntamente con el esposo o la esposa (para un individuo que estaba en unión cuando migró a los 30 años) es muy baja para el conjunto de los orígenes y sexos, con la excepción de los europeos comunitarios (ver figura 5). En ningún caso se supera una probabilidad del 55\%, lo que da idea de la importancia del efecto de separación o ruptura familiar que conlleva el proyecto migratorio. Por supuesto, este efecto habrá que ser matizado en función de la duración del periodo de separación, y en este sentido es interesante observar que la importancia del fenómeno de la reagrupación (ver figura 6) puede, en cierta manera, compensar esta primera visión que ofrece la situación a la llegada. En cuanto a las diferencias entre hombres y mujeres, sólo las africanas (y especialmente las marroquíes) presentan una probabilidad significativamente superior de migrar conjuntamente que sus compatriotas masculinos. En los demás grupos no se observa una diferencia por sexo destacable.

En la figura 6, comparamos entre colectivos la probabilidad de haber reagrupado a los cónyuges, entre aquellos individuos que llegaron a España solos pero tenían pareja. Como no se trata de una variable que conocemos en el momento de la llegada, como era el caso de los dos modelos anteriores, en este modelo hemos introducido los años de residencia como un elemento de control, puesto que asumimos (y así lo confirman los resultados) que la probabilidad de haber reagrupado crece con los años de residencia. Es importante señalar que no estamos hablando necesariamente de personas reagrupadas mediante un proceso de reagrupación legal, puesto que hay personas que

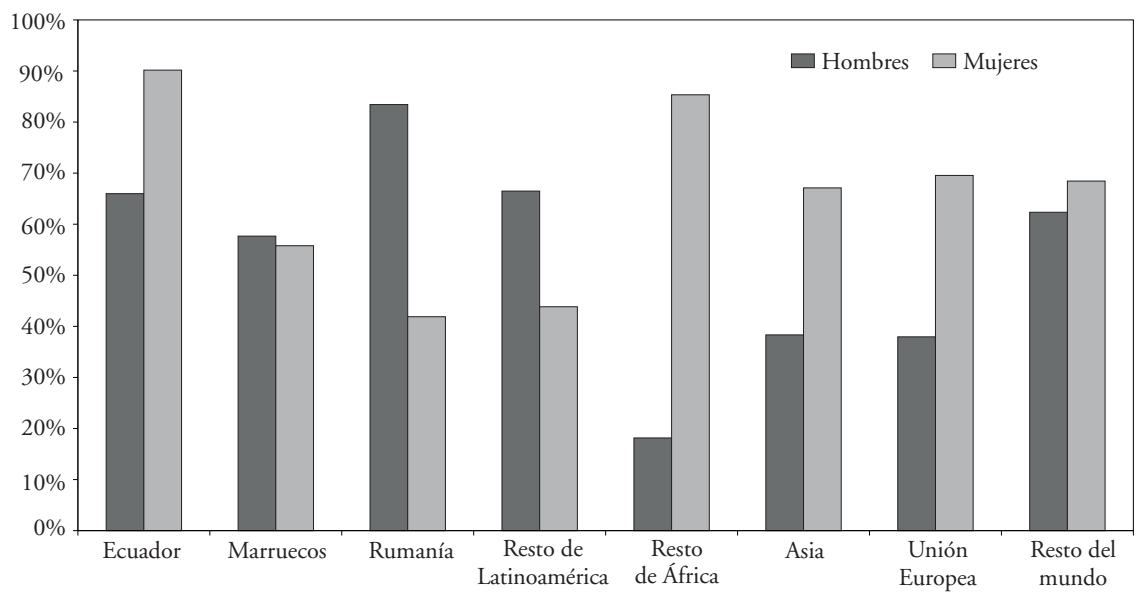

Figura 6. Probabilidad estimada de reagrupar a la pareja (en el caso de tenerla), por sexo.

Fuente: Elaboración propia.

Nota: Las probabilidades estimadas se han calculado a partir de las odds ratio que se presentan en el anexo y para un individuo tipo (estudios secundarios y que ha llegado a España después de 2006 a los 30 años). 
reagrupan de facto por la llegada de un familiar. Sin embargo, las diferencias entre colectivos en cuanto a su situación legal se deben tener en cuenta a la hora de explicar las diferencias entre ellos.

La probabilidad de nuestro inmigrante tipo con cinco años de residencia en España de haber reagrupado a su cónyuge, en el caso de haber llegado sin su pareja, varía en función del colectivo y entre hombres y mujeres. Destaca el hecho de que, en algunos grupos como el de los ecuatorianos, africanos, asiáticos o europeos, la probabilidad de haber reagrupado sea superior para las mujeres que para los hombres. Esto no significa que, en valores absolutos, las mujeres reagrupen más que los hombres, más bien que de las pocas mujeres que viajaron dejando a su esposo y que tienen opción de reagrupar, la mayoría lo hacen. En el caso de los hombres, es singular la bajísima probabilidad, inferior al 20\%, que tienen los africanos (excluyendo a Marruecos) de reagrupar a la esposa.

Finalmente, analizamos la probabilidad de haber formado pareja en España para aquellos que llegaron sin pareja. Los resultados de la figura 7 muestran la probabilidad de nuestro inmigrante tipo de haber formado pareja tras cinco años de residencia en España. En su conjunto, aproximadamente la mitad de los migrantes llegados a los 30 habrían formado pareja transcurridos estos cinco años. No se aprecian importantes diferencias entre hombres y mujeres ni entre grupos de origen. Quizás la única excepción sea la de las mujeres ecuatorianas, cuya probabilidad de formar pareja es la más alta con diferencia.

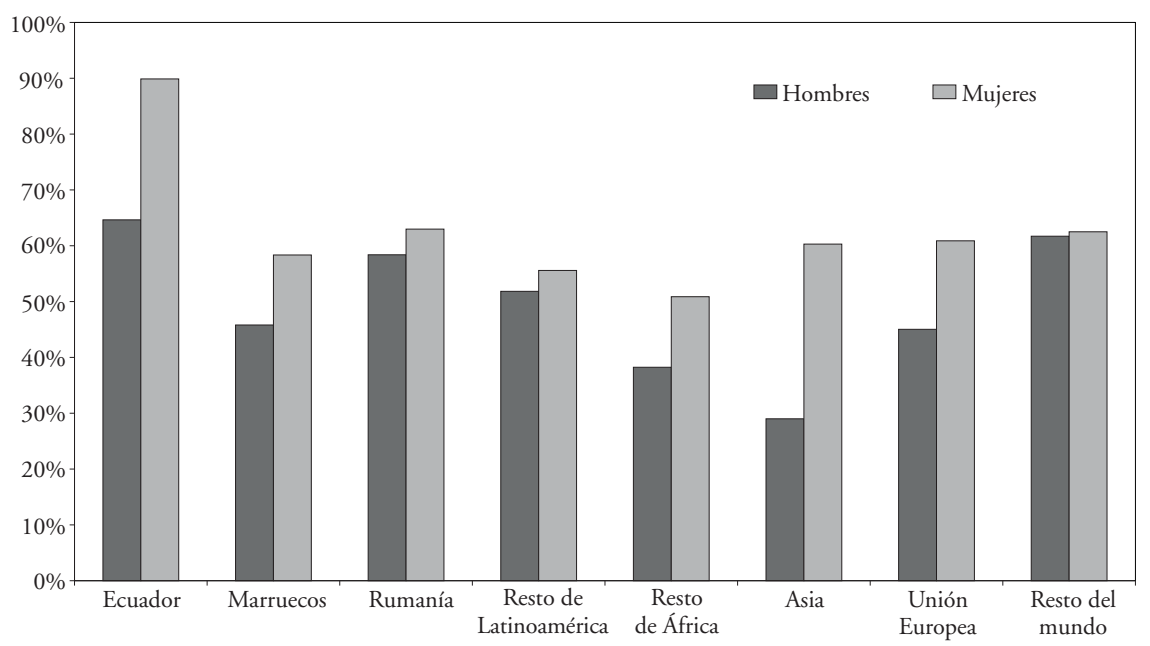

Figura 7. Probabilidad estimada de formar pareja en España (en el caso de haber migrado sin tener pareja), por sexo.

Fuente: Elaboración propia.

Nota: Las probabilidades estimadas se han calculado a partir de las odds ratio que se presentan en el anexo y para un individuo tipo (estudios secundarios, con cinco años de residencia en España y que ha llegado a los 30 años). 
De este análisis, se deduce que el comportamiento de los que llegaron solos y su participación en el mercado matrimonial son bastante uniformes. Otra cosa sería analizar no sólo si forman unión, sino con quién la forman. Si lo hacen con personas que ya residen en España o bien si lo hacen con personas de su mismo país de origen, es decir, importando al cónyuge. Si lo hacen con personas de su mismo origen, aunque la pareja se forme en España, o bien con cónyuges españoles. La evidencia previa sugiere que, en ese caso, las diferencias entre grupos y sexos serían claramente mayores (Cortina, Esteve y Domingo, 2008). Es esta materia para otro estudio.

\section{Conclusiones}

En este artículo, hemos investigado la situación de pareja de los inmigrantes internacionales antes, en el momento y después de la migración, con el objetivo de informar de la diversidad de situaciones en las que se encuentran. Para facilitar el análisis, hemos diseñado una clasificación de las trayectorias en seis grupos (más un grupo residual) basados en la situación de pareja de los inmigrantes en cada uno de estos momentos y hemos observado la distribución de estas trayectorias en función del colectivo y del sexo. Hemos basado nuestro estudio en la experiencia de España y hemos utilizado los datos de la Encuesta Nacional de Inmigrantes realizada en el año 2007. Los colectivos y los grupos de inmigrantes analizados son representativos de la inmigración española.

Los resultados muestran una diversidad de trayectorias de pareja en función de la edad de llegada, el sexo y el origen de los individuos. La edad, junto a otras variables, ha sido tratada como una variable de control. Nuestro interés principal radicaba en mostrar las diferencias por sexo y origen. La descripción de estas diferencias admite pocas generalizaciones y requiere más bien explicaciones específicas para cada grupo. Por lo general, las mujeres suelen migrar en un contexto de pareja en mayor proporción que los hombres. También son las que, en términos absolutos, son más reagrupadas que reagrupadoras y se emparejan en España ligeramente más que los hombres. Por colectivos, las diferencias por sexo más destacadas las observamos entre los africanos. Los hombres africanos que tienen pareja en el momento de migrar y que migran conjuntamente en caso de tenerla son relativamente muy pocos comparado con las mujeres africanas. En cambio, la inmigración latinoamericana presenta mayor similitud entre hombres y mujeres. En esta investigación, no nos hemos adentrado en los factores que están detrás de estas diferencias. Éstos obedecen a razones diversas relacionadas con la situación legal de los colectivos, los motivos de la migración, las características individuales de los migrantes o su adaptación a la sociedad de destino.

En cualquier caso, las diferencias entre colectivos nos ofrecen información sobre la naturaleza de los flujos, sobre las perspectivas de integración y/o retorno y sobre las pautas de comportamiento familiar de los inmigrantes. No todas las trayectorias llevan asociado el mismo coste en términos personales y familiares. La separación temporal de los cónyuges, que a menudo implica 
también la separación de los hijos, tiene un coste familiar clarísimo. Los africanos, por ejemplo, son el exponente más claro de migración mayoritariamente individual, protagonizada bien por individuos sin pareja o por individuos emparejados que raramente reagrupan. Esto nos ofrece un perfil, además de masculinizado, de migración laboral que implica la separación conyugal con escasa probabilidad de reagrupar (probablemente como consecuencia de las dificultades para llevar a cabo la reagrupación o bien porque las estrategias migratorias implican una menor duración). En el extremo opuesto, tenemos a los europeos, tanto hombres como mujeres, con un perfil dominado por la migración conjunta y la residencia de los cónyuges en el mismo hogar, es decir, con pocas parejas ausentes.

La dimensión familiar en las trayectorias migratorias que hemos querido explorar en esta investigación debería ampliarse más allá de la situación de pareja. Si ampliáramos esta dimensión a los hijos y a otros parientes, podríamos completar el análisis y matizar mejor las trayectorias identificadas. Las relaciones con el país de origen también aportarían información valiosa sobre el entramado familiar del migrante y el peso de la familia de origen en la estrategia laboral y familiar del migrante en el país de destino. Todos éstos son aspectos que se pueden incorporar al estudio con los datos de la Encuesta Nacional de Inmigrantes y que deberían ser tratados en futuras investigaciones. También será necesario valorar las implicaciones que las trayectorias de pareja tendrán sobre el comportamiento y la integración de los inmigrantes a nivel individual y colectivo (niveles de fecundidad, participación en el mercado laboral, etc.). Del mismo modo que se tienen en cuenta características individuales y colectivas de la población inmigrada para entender su integración en la sociedad de destino, también deberían considerarse los aspectos familiares.

Para poder examinar estos efectos, necesitamos tiempo y datos que nos permitan, en los próximos años, hacer un seguimiento de la población inmigrada y sus descendientes. El tiempo es necesario para observar cómo transcurre la adaptación de la población inmigrada en España, puesto que todavía estamos tratando con colectivos de llegada muy reciente, cuya situación actual puede deberse más a la breve duración de su presencia en el país que a singularidades específicas de los colectivos. Y los datos son necesarios para poder hacer un seguimiento de la evolución de los inmigrantes en el tiempo. Datos que, preferentemente, han de facilitar el análisis longitudinal. Si bien la Encuesta Nacional de Inmigrantes proporciona valiosa información biográfica de los inmigrantes, no admite la aplicación de modelos de historia de vida para analizar la formación de la pareja y su efecto en las trayectorias familiares y laborales de los inmigrantes. Desconocemos la historia de pareja de los individuos anterior a la unión actual y para las uniones consensuales no sabemos en qué año se formaron. A pesar de estas limitaciones, la Encuesta Nacional de Inmigrantes ha dado un gran impulso a la investigación sobre migración internacional en España.

Las implicaciones sociales y demográficas de las trayectorias de pareja aquí descritas son evidentes y necesitarán ser estudiadas en mayor profundidad 
en investigaciones futuras. De ellas dependerá en buena medida el potencial inmigratorio de los próximos años por reagrupación familiar, la participación de la población extranjera en el mercado matrimonial español y las expectativas de permanencia en el país. En este sentido, será necesario comparar las trayectorias observadas en España con las de otros países receptores. El contexto específico de la inmigración internacional en España se caracteriza por su novedad, intensidad y diversidad de orígenes. En sociedades con mayor tradición inmigratoria, los inmigrantes se integran en estructuras sociales y económicas establecidas antes de su llegada, que sin duda facilitan su integración en la sociedad de destino.

\section{Referencias bibliográficas}

Andersson, G. (2004). «Childbearing after Migration: Fertility Patterns of Foreignborn Women in Sweden». International Migration Review, 38 (2), 747-774.

Aparicio, R. et al. (2005). Marroquies en España: Sociedad, cultura y migraciones. Madrid: Universidad Pontificia Comillas de Madrid.

Arango, J. (2004). «La inmigración en España a comienzos del siglo xXI». En: Leal Maldonado, J. Informe sobre la situación demográfica en España. Madrid: Fundación Fernando Abril Martorell, 161-186.

Blank, S. y Torrecilha, R.S. (1998). «Understanding the living arrangements of Latino immigrants: A life course approach». International Migration Review, 32 (1), 3-19.

BorJaS, G.J. y Bronars, S.G. (1991). «Immigration and the Family». Journal of Labor Economics, 9, 123-48.

Boyd, M. (1989). «Family and Personal Networks in International Migration: Recent developments and New Agendas». International Migration Review, 23 (3), 638-670.

Boyle, P.; Feng, Z. y Gayle, V. (2009). «A New Look at Family Migration and Women's Employment Status». Journal of Marriage and Family, 417-431.

CARLSON, E. (1985). «The impact of international migration upon the timing of marriage and childbearing». Demography, 22 (1), 61-72.

Cооке, T.J. (2008). «Migration in a family way». Population Space and Place, 14 (4), 255-265.

Cortina, C.; Esteve, A. y Cabré, A. (2009). «¿Con quién se unen los latinoamericanos en España? Respuestas a partir de tres fuentes estadísticas». Notas de Población, 86, 19-38.

Cortina, C.; Esteve, A. y Domingo, A. (2008). «Marriage patterns of foreign born population in a new country of immigration: the case of Spain». International Migration Review, 42 (4), 877-902.

DinkeL, R.H. y Leвoк, U.H. (1997). «The fertility of migrants before and after crossing the border: the ethnic German population from the former Soviet Union as a case study». International Migration, 35 (2), 253-270.

Domingo, A. y GiL, F. (2007). «Immigration and Changing Labour Force Structure in the Southern European Union». Population - E (edición inglesa), 62 (4), 709-727.

GonzÁlez-Ferrer, A. (2008). Estrategias familiares y laborales en la emigración: Reagrupación familiar, elección de parejas y empleo de los inmigrantes en el pais de destino. Madrid: Consejo Económico y Social. 
González-Ferrer, A. y Cebolla, H. (2008). La inmigración en España (2000-2007). Madrid: Centro de Estudios Políticos y Constitucionales.

KaHn, J.R. (1988). "Immigrant selectivity and fertility adaptation in the United States». Social Forces, 67 (1), 108-128.

Kofman, E. (2004). «Family-Related Migration: A Critical Review of European Studies». Journal of Ethnic and Migration Studies, 30 (2), 243-262.

Massey, D. (1987). "Social Structure, Household Strategies and Cumulative Causation of Migration». Population Index, 56, 3-26.

Massey, D. y Malone, N. (2002). "Pathways to legal immigration». Population Research and Policy Review, 21, 473-504.

OECD (2008). International Migration Outlook, SOPEMI-2008. París: OECD.

Pagnini, D.L. y Morgan, S.P. (1990). «Intermarriage and social distance among U.S. Immigrants at the Turn of the Century». The American Journal of Sociology, 96 (2), 405-432.

Palloni, A. et al. (2001). «Social capital and international migration: A test using information on family networks». American Journal of Sociology, 106 (5), 12621298.

Reher, D. y Requena, M. (2009). «The National Immigrant Survey of Spain: A new data source for migration studies in Europe». Demographic Research, 20, 253-278.

Rogers, A. (1988). «Age Patterns of Elderly Migration: An International Comparison». Demography, 25 (3), 355-370.

Rogers, A.; Raquillet, R. y Castro, L. (1978). «Model migration schedules and their applications». Environment and Planning A, 10, 475-502.

SMiтh, D.P. (2004). "An "united" research agenda for family migration: loosening the "shakles" of the past». Journal of Ethnic and Migration Studies, 30 (2), 263-282.

Stark, O. y Bloom, D.E. (1985). «The New Economics of Labor Migration». The American Economic Review, 75, 173-178.

Strasser, E. et al. (2009). "Doing family: Responses to the constructions of "the migrant family" across Europe». The History of the Familiy (Families, Foreignness, Migration. Now and Then), 14 (2), 165-176.

VAN Hook, J. y GLICK, J.E. (2007). «Inmigration and living arrangements». Demography, 44 (2), 225-250.

Vila, M.R. y Castro-Martín, T. (2007). «Childbearing patterns of foreign women in a new immigration country: The case of Spain». Population, 62 (3), 419-450. 


\section{Anexo}

Tabla 1. Resultados de las regresiones logísticas (odds ratio)

\begin{tabular}{|c|c|c|c|c|}
\hline & $\begin{array}{l}\text { En pareja } \\
\text { al migrar }\end{array}$ & $\begin{array}{c}\text { Migración } \\
\text { conjunta }\end{array}$ & $\begin{array}{c}\text { Reagrupación } \\
\text { del cónyuge }\end{array}$ & $\begin{array}{l}\text { En pareja } \\
\text { tras migrar }\end{array}$ \\
\hline Variable & $\operatorname{Exp}(B)$ & $\operatorname{Exp}(B)$ & $\operatorname{Exp}(B)$ & $\operatorname{Exp}(B)$ \\
\hline \multicolumn{5}{|l|}{ Sexo (ref. = hombre) } \\
\hline Mujer & $0,74^{*}$ & 1,10 & 4,73 & $4,86^{* *}$ \\
\hline \multicolumn{5}{|l|}{ Origen (ref. = Ecuador) } \\
\hline Marruecos & $0,34^{* *}$ & $0,26^{* *}$ & 0,70 & $0,46^{* *}$ \\
\hline Rumanía & $0,72^{*}$ & $2,07^{* *}$ & $2,60^{* *}$ & 0,77 \\
\hline Resto de Latinoamérica & $0,62^{* *}$ & $1,99^{* *}$ & 1,02 & $0,59^{* *}$ \\
\hline Resto de África & $0,33^{* *}$ & $0,49^{* *}$ & $0,11^{* *}$ & $0,34^{* *}$ \\
\hline Asia & $0,52^{* *}$ & $0,57^{*}$ & $0,32^{* *}$ & $0,22^{* *}$ \\
\hline Unión Europea & $0,38^{* *}$ & $3,23^{* *}$ & $0,32^{* *}$ & $0,45^{* *}$ \\
\hline Resto del mundo & $0,65^{* *}$ & $1,75^{* *}$ & 0,85 & 0,88 \\
\hline Edad de llegada & $1,51^{* *}$ & $1,01^{*}$ & $1,19^{*}$ & $1,35^{* *}$ \\
\hline Edad de llegada ${ }^{2}$ & $1,00^{* *}$ & & $1,00^{* *}$ & $1,00^{* *}$ \\
\hline Nivel de instrucción & $0,71^{* *}$ & $1,11^{*}$ & 1,19 & 1,08 \\
\hline \multicolumn{5}{|l|}{$\begin{array}{l}\text { Periodo de llegada } \\
\text { (ref. = antes de 1996) }\end{array}$} \\
\hline A partir de 1996 & $1,34^{* *}$ & $0,66^{* *}$ & & \\
\hline Años de residencia & & & $1,59^{* *}$ & $1,29^{* *}$ \\
\hline Años de residencia ${ }^{2}$ & & & $0,99^{* *}$ & $1,00^{* *}$ \\
\hline \multicolumn{5}{|l|}{ Sexo $\mathrm{x}$ origen } \\
\hline Mujer x Marruecos & $2,72^{* *}$ & $7,87^{* *}$ & 1,58 & $2,73^{* *}$ \\
\hline Mujer x Rumanía & $1,82^{* *}$ & 1,14 & 0,90 & $2,00^{* *}$ \\
\hline Mujer x Latinoamérica & 1,07 & $0,64^{*}$ & 0,98 & $1,91^{* *}$ \\
\hline Mujer x Resto de África & $4,27^{* *}$ & $2,98^{* *}$ & $7,30^{*}$ & $2,75^{* *}$ \\
\hline Mujer x Asia & $1,71^{*}$ & 1,11 & 2,56 & $6,12^{* *}$ \\
\hline Mujer x Unión Europea & $1,87^{* *}$ & 1,08 & 2,87 & $3,13^{* *}$ \\
\hline Mujer x Resto del mundo & $1,49^{*}$ & 0,88 & 2,72 & $1,70^{*}$ \\
\hline Sexo x edad de llegada & & $0,98^{* *}$ & 0,96 & $0,95^{* *}$ \\
\hline Sexo x periodo de llegada & & $1,27^{*}$ & & \\
\hline Sexo $x$ años de residencia & & & $0,85^{* *}$ & $0,91^{* *}$ \\
\hline Constante & $0,00^{* *}$ & $0,41^{* *}$ & $0,01^{* *}$ & $0,00^{* *}$ \\
\hline$N$ & 9.965 & 4.318 & 1.439 & 5.165 \\
\hline
\end{tabular}

${ }^{*} p<0,05 ;{ }^{* *} p<0,01$

Nota: selección de migrantes llegados a España entre los 18 y los 49 años. 